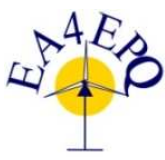

International Conference on Renewable Energies and Power Quality (ICREPQ'14)

Cordoba (Spain), $8^{\text {th }}$ to $10^{\text {th }}$ April, 2014

Renewable Energy and Power Quality. Fournal (RE\&PQJ)

ISSN 2172-038 X, No.12, April 2014

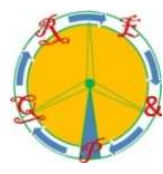

\title{
The Study of the Impacts Introduced by a Wind Farm, having Doubly Fed Induction Generators, on a Power System
}

\author{
M.A. Saqib ${ }^{1}$, S.A.R. Kashif ${ }^{2}$ and Q.Z. Mujahid ${ }^{3}$ \\ ${ }^{1,2}$ Department of Electrical Engineering, University of Engineering and Technology, Lahore \\ ${ }^{3}$ GE International Inc., 234 MW Muridke Power Station, 10-km Sheikupura-Muridke Road, Sheikhupura \\ Emails: ${ }^{1}$ saqib@uet.edu.pk, ${ }^{2}$ abdulrahman@uet.edu.pk, ${ }^{3}$ Qamar.Mujahid@ge.com
}

\begin{abstract}
The paper discusses the 5th order model of a doubly fed induction generator which is used to study the impacts of a wind farm at the power system. The integration of wind farms poses serious problems on the stability of a power system. The study also illustrates the need for reactive power compensation when a wind generator is to be connected to a power system. A realistic 50 MW wind farm, proposed in the southern Sindh province of Pakistan, is being simulated to illustrate the dynamics of this integration on the national grid. This preliminary study assumes a constant wind speed for the duration of the studied period.
\end{abstract}

\section{Introduction}

The power transmission networks regulators, in different countries, establish their own Grid Codes which set out principles and procedures for a new connection to bulk transmission systems [1]. The grid integration of wind farms poses stability, control and power quality issues as the wind turbine generators (WTGs) are of asynchronous type with their characteristics different from those of typical synchronous generators [2]. In order to be integrated into a power grid, which in most cases, is dominated by conventional generators of synchronous type, wind farms are required to meet the same Grid Codes' requirements. However, asynchronous generators, i.e. induction generators do not provide ancillary services to the grid such as voltage and frequency control, VAR generation and low-voltage ride through (LVRT) capability [3].

The doubly-fed induction generator (DFIG) is the most commonly used technology in the wind generators, which provides variable-speed operation. The paper discusses the $5^{\text {th }}$ order model of a DFIG, and implements this model in the study of the dynamics of a practical power system to which a $50 \mathrm{MW}$ wind farm is proposed. A practical wind farm has a smooth source of reactive power supply, generally a FACT device, such as SVC or a STATCOM to meet the variable requirement of reactive power both in the normal - steady state and dynamic - and faulty operating conditions: in faulty operating conditions the requirement of reactive power compensation becomes more stringent as the wind farm is required to meet its LVRT capability. The paper also illustrates the need for such a source, of reactive power compensation, on the basis of the results being obtained in this study. The study does not assume a FACT device coupled with the DFIG whose effect on the system is being studied here. The other components of the system have also been modelled in MATLAB SIMULINK: the parameters have been chosen as to make the system a realistic one.

Section 2 gives a brief description of a DFIG. The $5^{\text {th }}$ order model of the machine is given in section 3. Simulink models of the wind farm employing a DFIG and the power system at the point of common coupling (PCC), where the wind farm is to be connected, are presented in section 4 . The simulated results are presented in section 5, and are discussed in section 6 .

\section{Configuration of a DFIG}

The configuration of a typical DFIG system is shown in Fig. 1.

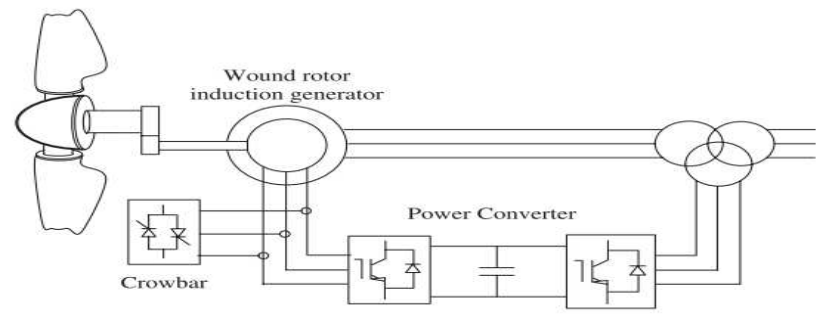

Fig. 1: Typical configuration of a DFIG. 
Slip rings take current out or into the rotor windings. The crow bar protects against over currents. Variable-speed operation is obtained by injecting a controllable voltage into the rotor at slip frequency. Rotor winding is fed through a variablefrequency power converter, typically through two AC/DC voltage source converters linked by a DC bus. The power converter decouples network electrical frequency from the rotor mechanical speed. Power is delivered to the grid through stator and rotor, and rotor can also absorb power. When rotor speed is higher than the synchronous speed power is delivered to the grid from the rotor; otherwise, when its speed is lower than the synchronous speed, the direction of power is from the grid to the rotor [4].

\section{Dynamic Modelling of the DFIG -Key Points}

The purpose is to have a model that could represent the dynamic behaviour of the system. The three-phase winding, connected to a three-phase source, produce a rotating magnetic field. This rotating magnetic field, which can be represented by two coils on the d-axis and the other on q-axis, rotates at the synchronous speed of the supply voltage. Three-phase voltages of slip frequency, $\mathrm{sf}_{\mathrm{s}}$, are induced on the rotor when stator magnetic field cuts the rotor conductors. As a result threephase current at slip frequency flows through the rotor conductors. These rotor currents also produce a rotating magnetic field which rotates at slip speed $\left(\omega_{\mathrm{s}}-\omega_{\mathrm{r}}=\mathrm{s} \omega_{\mathrm{s}}\right)$ with respect to the rotor. A viewer standing on the Earth would see the rotor magnetic field also rotating at the synchronous speed $\left(\mathrm{s} \omega_{\mathrm{s}}+\omega_{\mathrm{r}}=\omega_{\mathrm{s}}\right)$. Therefore, rotor magnetic field can also be represented by d- and q-axes. In synchronous reference frame all the coils are thus stationary, and inductances are constant. Now the machine's voltage and flux equations can be expressed in dq components. Complete modelling of the DFIG (5th order including stator and rotor transients, and damper windings) has been implemented in MATLAB SIMULINK.

Synchronously rotating reference frame has been selected to model a DFIG. The generator convention of sign has been used for the equations, i.e. the active and reactive powers have positive sign while feeding into the grid. The equations, in per unit, can be written [1], [5]:

Stator voltage equations are:

$$
\begin{gathered}
V_{q s}=\frac{1}{\omega_{\mathrm{b}}} * \frac{d \psi_{q s}}{d t}+\frac{\omega}{\omega_{\mathrm{b}}} * \psi_{d s}-\frac{r_{s}\left(\psi_{m q}-\psi_{q s}\right)}{x_{l s}} \\
V_{d s}=\frac{1}{\omega_{\mathrm{b}}} * \frac{d \psi_{d s}}{d t}+\frac{\omega}{\omega_{\mathrm{b}}} * \psi_{q s}-\frac{r_{s}\left(\psi_{m d}-\psi_{d s}\right)}{x_{l s}}
\end{gathered}
$$

where the stator voltages, in $\mathrm{d}-\mathrm{q}$ components, have been expressed in terms of corresponding flux linkages (subscripts
' $\mathrm{m}$ ' shows corresponding mutual flux linkages), stator resistance, leakage reactance and speed $\left(\omega_{\mathrm{b}}\right.$ is the base speed).

Similarly, rotor voltage equations are:

$$
\begin{gathered}
V_{q r}=\frac{1}{\omega_{\mathrm{b}}} * \frac{d \psi_{q r}}{d t}+\frac{\omega-\omega_{\mathrm{r}}}{\omega_{\mathrm{b}}} * \psi_{d r} \\
-\frac{r_{r}\left(\psi_{m q}-\psi_{q r}\right)}{x_{l r}} \\
V_{d r}=\frac{1}{\omega_{\mathrm{b}}} * \frac{d \psi_{d r}}{d t}+\frac{\omega-\omega_{\mathrm{r}}}{\omega_{\mathrm{b}}} * \psi_{q s} \\
-\frac{r_{r}\left(\psi_{m d}-\psi_{d r}\right)}{x_{l r}}
\end{gathered}
$$

Mutual flux linkage equations are:

$$
\psi_{m q}=x_{m}\left(i_{q s}+i_{d r}\right)
$$

$$
\psi_{m d}=x_{m}\left(i_{d s}+i_{d r}\right)
$$

where $x_{m}$ is the mutual reactance.

Stator current equations are:

$$
\begin{gathered}
i_{q s}=\frac{\left(\psi_{q s}-\psi_{m q}\right)}{x_{l s}} \\
i_{d s}=\frac{\left(\psi_{d s}-\psi_{m d}\right)}{x_{l s}}
\end{gathered}
$$

Rotor current equations are:

$$
i_{q r}=\frac{\left(\psi_{q r}-\psi_{m q}\right)}{x_{l r}}
$$

$$
i_{d r}=\frac{\left(\psi_{d r}-\psi_{m d}\right)}{x_{l r}}
$$

The flux linkage equations thus become: 


$$
\psi_{q s}=x_{m} i_{q r}+x_{l s} i_{q s}
$$

$$
\psi_{d s}=x_{m} i_{d r}+x_{l s} i_{d s}
$$

$$
\psi_{q r}=x_{m} i_{q s}+x_{l r} i_{q r}
$$

$$
\psi_{d r}=x_{m} i_{d s}+x_{l r} i_{d r}
$$

The electrical torque equation can be written as (generator sign convention):

$$
T_{e}=- \text { pair of poles } *\left(\psi_{d s} * i_{q s}-\psi_{q s} * i_{d s}\right)
$$

The rotational speed of the generator can be calculated using the swing equation as:

$$
\omega_{r}=\frac{\omega_{b}}{2 H} \int\left(T_{e}-T_{m}\right) d t
$$

where $H$ is the per unit inertia constant and defined as the ratio of kinetic energy in $\mathrm{MJ}$ at rated speed to the machine rating in MVA.

The active and reactive power for the stator and rotor can be calculated as:

$$
\begin{gathered}
P_{s}=V_{d s} i_{d s}+V_{q s} i_{q s} \\
Q_{s}=V_{q s} i_{d s}-V_{d s} i_{q s} \\
P_{r}=V_{d r} i_{d r}+V_{q r} i_{q r} \\
Q_{r}=V_{q r} i_{d r}-V_{d r} i_{q r}
\end{gathered}
$$

By using stator flux orientation (SFO), q-axis flux linkage vector is oriented along q-axis of synchronously rotating reference frame and hence $\psi_{q s}=0$ and $\psi_{d s}=\psi_{\mathrm{s}}$ (total stator flux linkage) and the stator current, in q \& d axes, becomes:

$$
i_{q s}=-\frac{x_{m}}{x_{l s}} i_{q r}
$$

$$
i_{d s}=\frac{\psi_{s}}{x_{l s}}-\frac{x_{m}}{x_{l s}} i_{d r}
$$

The stator resistance $r_{s}$ is assumed to be negligible, and applying stator voltage orientation (SVO) vector representation $V_{q s}=\mathrm{V}_{\mathrm{s}}$ (total stator voltage) and $V_{d s}=0$. The simplified electrical torque, stator active $\&$ reactive power equations can be written as:

$$
T_{e}=\frac{x_{m}}{x_{l s}} \psi_{s} i_{q r}
$$

$$
P_{s}=-\frac{x_{m}}{x_{l s}} V_{s} i_{q r}
$$

$$
Q_{s}=V_{s} \frac{\psi_{s}}{x_{l s}}-\frac{x_{m}}{x_{l s}} V_{s} i_{d r}
$$

\section{Simulink Model of the Overall System}

A $50 \mathrm{MW}$ wind form, proposed in District Thatta of Sindh, [6] has been simulated in MATLAB-SIMULINK by using the $5^{\text {th }}$ degree model of its DFIG that could represent the dynamic behaviour of the system and its impacts on power system. The aggregate model of wind turbines $(20 \times 2.5 \mathrm{MW}$, Nordex $\mathrm{N} 100$ ) are connected to $660 \mathrm{~V}$ bus (B660), which is in fact a three-phase VI measurement block. The $660 \mathrm{~V}$ bus (B660) is connected to the LV side of equivalent model of GSU (Generator Step Up) transformers $(0.66 / 22 \mathrm{kV}, 20 \times 3 \mathrm{MVA})$ which steps up the voltage to $22 \mathrm{kV}$. The equivalent model of $24 \mathrm{~km}$ collector cables (240 $\mathrm{mm}^{2} \mathrm{x}$-section) is connected between the $\mathrm{HV}$ side of the GSU transformer and the substation medium voltage $22 \mathrm{kV}$ bus (B22). Local auxiliary load of wind farm $(500 \mathrm{~kW})$ is connected to MV bus (B22). The equivalent model of the substation step-up transformer $(22 / 132 \mathrm{kV}, 60 \mathrm{MVA})$ is connected between the MV bus and the substation $132 \mathrm{kV} \mathrm{HV}$ bus (B132) which is also the point of common coupling (PCC) for the wind farm. A grounding transformer with neutral grounding resistor (NGR) is connected to the LV side of the substation step-up transformer. 
An equivalent model of the transmission line is connected between the substation HV bus and the receiving substation of the external grid (HESCO network of Pakistan). A site specific measurement block is connected at the PCC. The overall system is shown in Fig. 2.

\section{Simulation Results}

The simulation was run by keeping the wind speed constant at $10 \mathrm{~m} / \mathrm{s}$ with no fault or any disturbance on the external $132 \mathrm{kV}$ HESCO grid. The output blocks were configured to display the results at various buses, e.g. at $660 \mathrm{~V}, 22 \mathrm{kV}$ and $132 \mathrm{kV}$. However, the results at $132 \mathrm{kV}$, which is the point of common coupling, are presented here. Fig. 3 shows the active power, reactive power, power factor, voltage, current, frequency and rotor speed at the point of common coupling.

\section{Discussion}

The voltage at the $132 \mathrm{kV}$ bus is fairly stable, but is lower than the rated value: its value is around $0.8 \mathrm{pu}$. The current being supplied by the machine at the PCC is around 0.9 per unit and then it drops to around $0.25 \mathrm{pu}$ at $2 \mathrm{~s}$. The output power has a maximum value of around $0.82 \mathrm{pu}$, in the beginning, and then it decreases to around 0.4 pu toward the end $(10 \mathrm{~s})$. This shows that the machine is not producing the rated power at the wind speed of $10 \mathrm{~m} / \mathrm{s}$. The DFIG, being a type of induction machine, has a typical dynamic behaviour at the start up where its current is quite high and then becomes steady after some time. This decreased current is also associated with the reduced power being supplied by the machine. The machine requires reactive power from the system to operate; which is being indicated by the negative value of reactive power after $1 \mathrm{~s}$ : the machine is rather taking power from the system.

The scenario presented in this paper clearly illustrates the need for reactive power compensation for the operation of a windturbine generator. The purpose of this study has been to illustrate the importance of the $5^{\text {th }}$ order modelling of DFIG for the dynamic behaviour (not the working of a wind farm equipped with a reactive power compensation mechanism such as being provided by a FACT device, e.g. an SVC or STATCOM). The purpose is achieved as the $5^{\text {th }}$ degree model shows more transients of various electrical quantities than what can be expected from a conventional 3rd degree model of the DFIG. The $5^{\text {th }}$ degree model gives deep insight into the dynamics of the machine as compared to those obtained with a $3^{\text {rd }}$ degree model. Minute details can be obtained in various electrical parameters, and thus studied, with this modelling. The dynamic behaviour of a system, both in the healthy and faulty conditions, can be modelled in the $5^{\text {th }}$ degree for deep understanding and stability of the system.

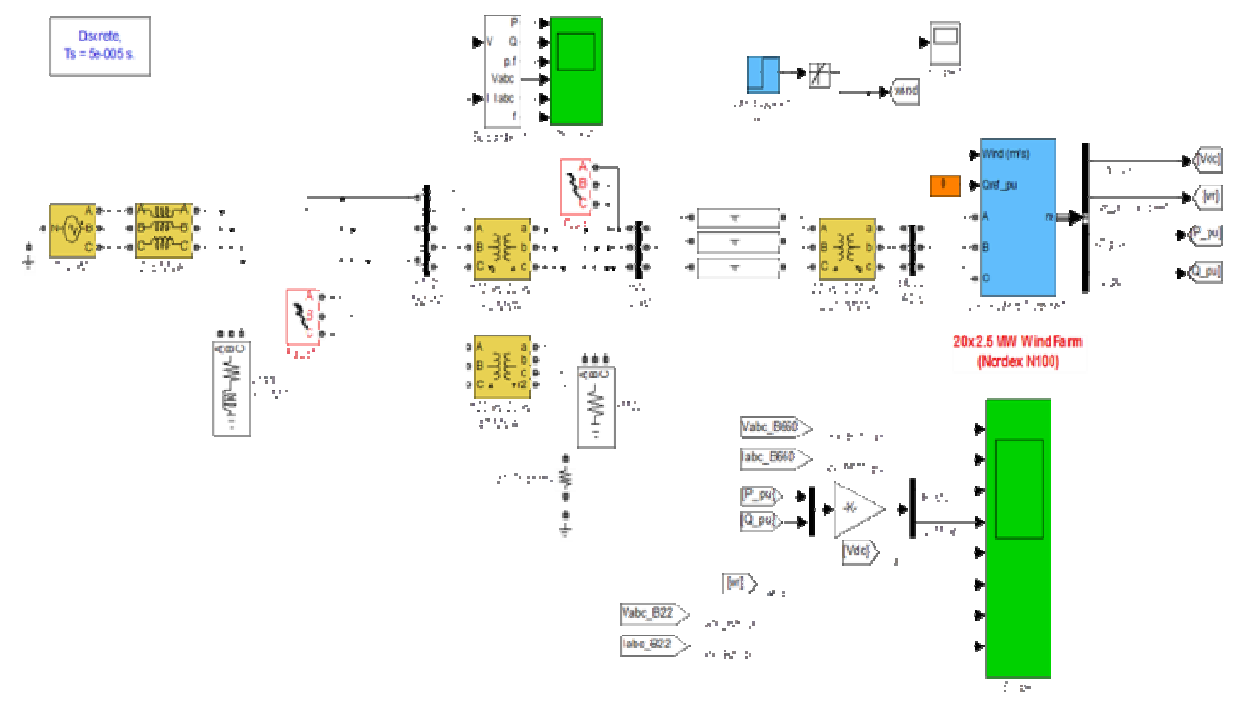

Fig. 2: Test system prepared for the study.

The study also illustrates the importance of the reactive power compensation in the accurate operation of a wind farm. The reactive power requirement will not fulfilled by fixed or switchable power capacitors (having discrete values). As the speed of the wind is variable, and at this variable speed, the reactive power requirement will also be variable which can only be met by a FACT device such as SVC or STATCOM capable of smoothly providing/absorbing reactive power from minimum to maximum value. The requirement of reactive 
power compensation becomes more stringent during a disturbance or fault conditions on the system.
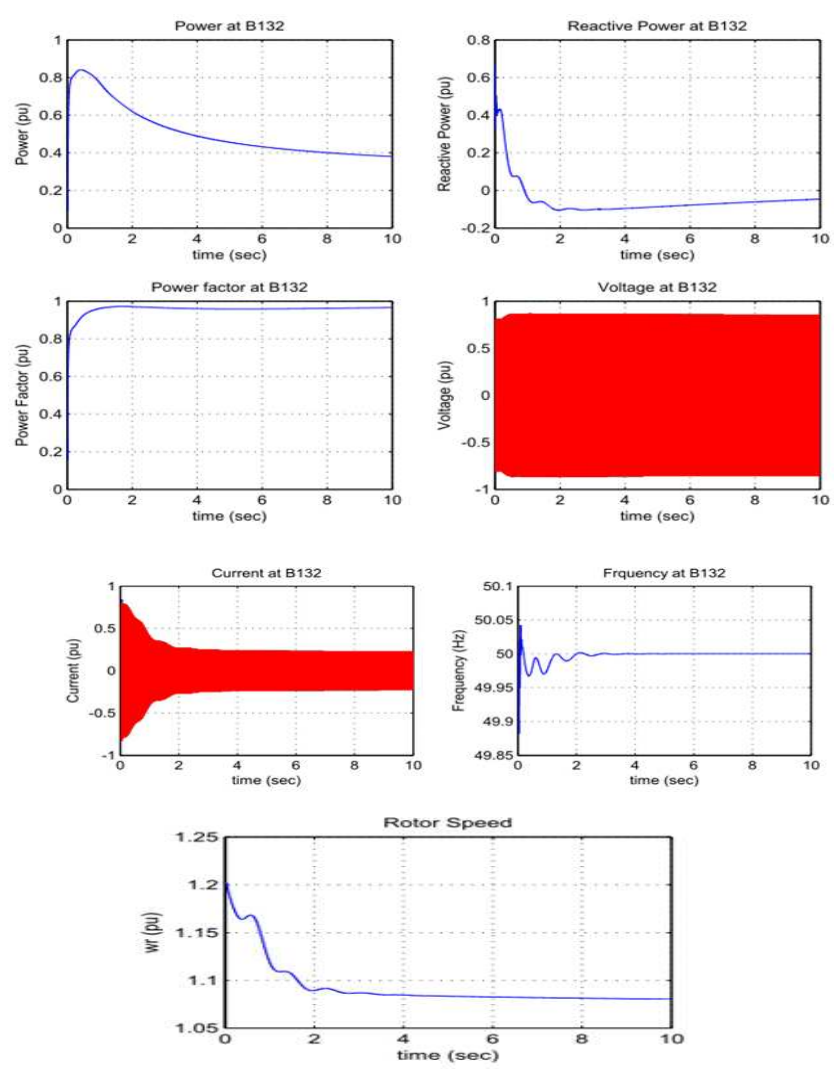

Fig. 3: Simulated results at the point of couple coupling.

\section{Conclusion}

The $5^{\text {th }}$ order model of a DFIG generator gives more insights into the dynamic behaviour of the system to which a wind farm is integrated. Generally a $3^{\text {rd }}$ order model of the machine DFIG - is used in studies which is incapable of showing the transients which may be present in an actual system. Without a variable and smooth reactive power compensation device such as SVC or STATCOM a wind farm is going to severely affect the stability of a power system.

\section{References}

O. Anaya-Lara, N. Jenkins, J. Ekanayake, P. Cartwright and M. Hughes, Wind Energy Generation: Modeling and Control, John Wiley \& Sons, 2009

[2]

J. G. Slootweg, "Wind power: modelling and impacts on power system dynamics", PhD Thesis, Technical University of Delft (Netherlands), 2003.
S. Heier, Grid Integration of Wind Energy Conversion Systems, John Wiley \& Sons, 2006.

B. Fox, D. Flynn, L. Bryans, N. Jenkins, D. Milborrow, M. O'Malley, R. Watson, R. and O. Anaya-Lara, "Wind power integration: connect and system operational aspects", IET Power and Energy Series, Vol. 50, Institution of Engineering and Technology, Stevenage, ISBN 10: 0863414494, 2007.

M. M. Billah, N. Hosseinzadeh, M. M. Ektesabi, "Modelling of a doubly fed induction generator (DFIG) to study its control system", Proceedings of the $20^{\text {th }}$ Australasian Universities Power Engineering Conference (AUPEC 2010), Christchurch, New Zealand, 05-08 December 2010.

A.Z. Saleem, "Techniques for grid code compliant integration of wind farms in Pakistan", M.Sc. Thesis, Department of Electrical Engineering, University of Engineering and Technology, Lahore, 2012. 